\title{
Is Anatomy Dead?
}

\author{
Godwin Tong* \\ College of Medical and Dental Sciences, University of Birmingham, UK
}

Submission: September 05, 2018; Published: September 10, 2018

*Corresponding author: Godwin Tong, College of Medical and Dental Sciences, University of Birmingham, UK, Tel: +44 7415207196;

Email: GXT545@bham.ac.uk

\section{Abstract}

Anatomy is often said to be the bread and butter of doctors, but in light of the ever-increasing additions to medical curricula and difficulties in teaching the subject, Anatomy has dropped out of favour with both staff and students, making way for the teaching of other new exciting specialties. In this paper, we highlight some of the new advances Anatomy has made in the recent years, demonstrating the relevance and potential clinical implications these discoveries can have, thus supporting the notion that Anatomy as a subject is still very much alive and exciting as it was in the early days.

Keywords: Anatomical education; Medical curriculum; Advances in anatomy

\section{Introduction}

Anatomy has always been the cornerstone of medical education, even from the early 1200 s, and its teaching has been centred around dissection for centuries. With the ever-increasing undergraduate curricula, the amount of time dedicated to anatomy teaching has steadily decreased. Furthermore, it does not help that the amount of anatomists are dwindling in many medical schools worldwide [1]. The decline of anatomy teaching has been noted by medical students and doctors alike [2]. For many years and conversely, there has been in a significant increase in medical negligence cases revolving around "surgical disasters". At least for the National Health Service of the United Kingdom, a national level audit [3] reported a 7-fold increase in negligent episodes over a period of 5 years, creating a $£ 2.6$ billion economic liability. These claims could be due to a myriad of factors - such as ever-increasing patient expectations - but it is no doubt that a lack of a solid anatomy foundation could be one of the causes as well [4]. It could be argued that the root cause of these problems is due to the reduced emphasis of anatomy in the modern-day curriculum with the emergence of new and exciting specialties. Anatomy as a subject has suffered because of its failure to evolve and adapt quickly enough. It has been accused of being mundane, archaic, excessive, redundant and unable to adapt to modern educational methods. Furthermore, with dissection appearing to be a dying art with lesser schools offering it in their curriculum, the teaching of anatomy has been undertaken via other methods. As such, it comes as no surprise that it is a common gripe amongst students [5] that learning anatomy is boring as it is just about memorising a set list of information and regurgitating it during examinations.

\section{Anatomy's Victories}

Interestingly, Anatomy as a subject has had several small victories over the years that deserve more credit and attention. These lend credence to the notion that anatomy is not dead and there is always something new to learn. From a macroscopic perspective, in 2013, news reports around the world exclaimed the discovery of a new ligament in the knee by Belgian surgeons [6]. the anterolateral ligament (ALL). Truth is, the ALL had been sporadically reported in several previous papers, but with varying descriptions, and few took note of it. The ALL is a true ligament which originates from the prominence of the lateral femoral epicondyle, has an oblique course to the anterolateral aspect of the proximal tibia and attaching to the lateral meniscus. Despite ACL reconstructions being a common procedure with high success rates [7], a positive "pivot-shift" test following ACL reconstruction is observed in up to $30 \%$ of cases after ACL surgery and is responsible for secondary meniscal and cartilaginous problems $[8,9]$ The discovery and characterisation of the ALL has led to further studies determining that it plays a major role controlling internal tibial rotation whereas the ACL only plays a minor role [10]. Since it provides stability to the anterolateral capsule, it is increasingly suggested that patients with anterolateral rotational instability, such as those with Segond fractures, should be screened for potential ALL tears [11]. Indeed, a meta-analysis [12]. has shown that a combined reconstruction approach provides the best reduction of the pivot-shift phenomenon.

Microscopically, advances have been made with regards to the anatomy of the sperm. The flagellum of the sperm is 
known to have 3 distinct segments: the mid piece containing the mitochondrion, the principal piece containing the axoneme - a complex arrangement of nine doublet microtubules surrounding two singlet central pair microtubules -and lastly, the terminal piece [13]. Up to recently, only two microtubule-associated proteins (tau and tubulin acetylase) have been reported to reside within the microtubules [14]. Recent studies [15]. have shown that other proteins do indeed localise inside microtubules. By making use of cryo-electron tomography, it is now reported by [7] that a novel protein complex called the Tail Axoneme IntraLumenal Spiral (TAILS) spanning several micrometers reside in the lumens of all healthy human spermatozoa axonemal microtubules at the distal end. It was hypothesised by the authors that the spiral complex may have several functions, including aiding motility, providing structural support, maintaining microtubule turnover and determining the direction in which the sperm swims. This is certainly exciting as it raises questions for future research. Is the TAILS complex unique to humans? Is the complex essential for sperm motility? Since sperm motility and morphology are directly associated with male fertility, is there a role for the TAILS complex in solving problems with male infertility and thus improving current techniques in artificial fertilisation? Certainly, this discovery highlights the lack of information we have from a microscopical perspective and the relevance of emerging technology like cryo-electron tomography which can be used to elucidate new anatomical facts.

The anatomy of the human brain has also made huge leaps forward, with the Human Connectome Project and the Allen Brain Atlas being at the forefront. Making an accurate brain map has been a century-old goal of neuroscientists in hopes of unravelling what each and every part of the brain does. The Allen Brain Atlas [16]. provides complete high-resolution whole brain imaging data consisting of magnetic resonance imaging and diffusion weighted imaging complete with cellular level architecture data from Nissl stains. This wealth of data is available free and online, allowing people to access neuroanatomical data from the macro level all the way down to the cellular level. However, the data is based on a single 34-year-old lady post-mortem and might have limited generalisability. The Human Connectome Project (HCP) [17], on the other hand, is a brain map derived from magnetic resonance imaging from 210 healthy adult's post-mortem. This project characterised 97 new cortical areas of the brain, which may yield new insights in human evolution and brain functions when compared to nonhuman primates or rodents which are commonly used models of neuroanatomy. One exciting area this technology can be applied to is the pathophysiology of neurological disorders like Alzheimer's Disease (AD). AD is characterised by distinct tissue changes associated with accumulation of extracellular amyloid- $\beta(A \beta)$ peptides and intracellular deposition of hyperphosphorylated tau. It has been shown that $A \beta$ and tau aggregates play a central role for $\mathrm{AD}$ pathogenesis by triggering neurodegenerative processes in the brain [18]. Microglia is also closely associated with clinical features of $\mathrm{AD}$ in brains from $\mathrm{AD}$ patients and $\mathrm{AD}$ mouse models [20-27]. For example, acutely activated microglia express cytokines which drive enhanced phagocytosis and clearance of $A \beta$, while chronic activation of microglia drives a chronic inflammatory state giving rise to neurotoxicity and neurodegeneration. As such, using data from the HCP and Allen Brain Atlas, one could look to answer questions regarding the gender bias of $\mathrm{AD}$ prevalence [19] by studying the distribution of endogenous microglia in both sexes.

\section{Conclusion}

Taken together, these victories along with many others, challenge the notion that we already know everything there is to know about anatomy. With the advent of new imaging modalities at the microscopic level, anatomy can be rediscovered with many clinical implications and thus be restored to its glory days. Anatomy is still relevant - and certainly not dead - as long as we possess and emulate the thirst for knowledge that our predecessor anatomists had.

\section{Declaration of Interest}

The author reports no conflicts of interest. The author alone is responsible for the content and writing of this article.

\section{Acknowledgements}

The authors would like to thank Mr Ethan Khoo (Nanyang Technological University, Singapore) and Inez Dale-Jones (University of Birmingham) for comments and critical reading of the manuscript.

\section{References}

1. (2003) Anatomy Classes Face Gross Shortage. Science 299(5611): $1309 \mathrm{c}-1309 \mathrm{c}$.

2. Cottam WW (1999) Adequacy of medical school gross anatomy education as perceived by certain postgraduate residency programs and anatomy course directors. Clin Anat 12: 55-65.

3. Gautam V, D Avanzo C, Berezovska O, Tanzi R E, Kovacs DM (2015) Synaptotagmins interact with APP and promote $A \beta$ generation. Mol. Neurodegeneration 10: 31.

4. Penazzi L, Tackenberg C, Ghori A, Golovyashkina N, et al. (2016) $\mathrm{A} \beta$-mediated spine changes in the hippocampus are microtubuledependent and can be reversed by a subnanomolar concentration of the microtubule-stabilizing agent epothilone D. Neuropharmacology 105: 84-95.

5. Brown JR, Schwartz C, Heumann JM, Dawson SC, Hoenger A (2016) A detailed look at the cytoskeletal architecture of the Giardia lamblia ventral disc. J Struct Biol 194(1): 38-48.

6. Ding SL, Royall JJ, Sunkin SM, Ng L Facer, B A C, Lesnar, et al. (2016) Comprehensive cellular-resolution atlas of the adult human brain: Adult human brain atlas. J Comp Neurol 524(16): 3127-3481.

7. Claes S, Vereecke E, Maes M, Victor J, Verdonk, Bellemans J (2013) Anatomy of the anterolateral ligament of the knee. J Anat 223: 321328.

8. Wilde J, Bedi A, Altchek DW (2014) Revision Anterior Cruciate Ligament Reconstruction. Sports Health 6(6): 504-518. 
9. Monaco E, Ferretti A, Labianca L, Maestri B, A. Speranza, et al. (2012) Navigated knee kinematics after cutting of the ACL and its secondary restraint. Knee Surg Sports Traumatol Arthroscopy 20(5): 870-877.

10. Monaco E, Maestri B, Labianca L, Speranza A et al (2010) Navigated Knee Kinematics After Tear of the ACL and Its Secondary Restraints: Preliminary Results. Orthopedics 33(10): 87-93.

11. Parsons EM, Gee AO, Spiekerman C, Cavanagh PR (2015) The Biomechanical Function of the Anterolateral Ligament of the Knee. Am. J. Sports Med. 43(3): 669-674.

12. Roessler PP, Schüttler KF, HeyseTJ, Wirtz DC, Efe T (2016) The anterolateral ligament (ALL) and its role in rotational extra-articular stability of the knee joint: a review of anatomy and surgical concepts. Arch Orthop Trauma Surg 136(3): 305-313.

13. Hewison CE, Tran MN, Kaniki N, Remtulla A, Bryant D, Getgood AM (2015) Lateral Extra-articular Tenodesis Reduces Rotational Laxity When Combined with Anterior Cruciate Ligament Reconstruction: A Systematic Review of the Literature. Arthrosc J Arthrosc Relat Surg 31(10): 2022-2034

14. Zabeo D, Heumann JM, Schwartz CL, Suzuki Shinjo A, et al. (2018) A lumenal interrupted helix in human sperm tail microtubules. Sci Rep 8: 2727

15. Wilde J, Bedi A, Altchek DW (2014) Revision Anterior Cruciate Ligament Reconstruction. Sports Health 6(6): 504-518.

16. Gautam V, D Avanzo C, Berezovska O, Tanzi R E, Kovacs DM (2015) Synaptotagmins interact with APP and promote A $\beta$ generation. Mol Neurodegeneration 10: 31

17. Laws KR, Irvine K, Gale TM (2016) Sex differences in cognitive impairment in Alzheimer's disease. World J Psychiatry 6(1): 54-65.
18. Glasser MF, Coalson TS, Robinson EC, Hacker CD et al. (2016) A multimodal parcellation of human cerebral cortex. Nature 536: 171-178.

19. Sarlus H, Heneka MT (2017) Microglia in Alzheimer's disease. J Clin Invest 127: 3240-3249.

20. Santwana Kar, Juan Fan, Michael J Smith, Michel Goedert, Linda A Amos (2003) Repeat motifs of tau bind to the insides of microtubules in the absence of taxol. EMBO J 22: 70-77.

21. Kemeir M (2012) Attitudes and views of medical students toward anatomy learnt in the preclinical phase at King Khalid University. J Fam Community Med 19(3) 190-193.

22. McCuskey RS, Carmichael SW, Kirch DG (2005) The importance of anatomy in health professions education and the shortage of qualified educators. Acad Med J Assoc. Am Med Coll 80(4): 349-351.

23. Parsons EM, Gee AO, Spiekerman C, Cavanagh PR (2015) The Biomechanical Function of the Anterolateral Ligament of the Knee. Am. J. Sports Med. 43(3): 669-674.

24. Hardy J, Dennis J Selkoe (2002) The Amyloid Hypothesis of Alzheimer's Disease: Progress and Problems on the Road to Therapeutics. Science 297(5580): 353-356.

25. Habbal 0 (2009) The State of Human Anatomy Teaching in the Medical Schools of Gulf Cooperation Council Countries: Present and future perspectives. Sultan Qaboos Univ Med J 9(1): 24-31.

26. Mitchell R, Batty L (2009) Undergraduate perspectives on the teaching and learning of anatomy. ANZ J Surg 79: 118-121.

27. Drake RL, McBride JM, Pawlina W (2014) An update on the status of anatomical sciences education in United States medical schools. Anat Sci Educ 7: 321-325.

\section{Your next submission with Juniper Publishers} will reach you the below assets

- Quality Editorial service

- Swift Peer Review

- Reprints availability

- E-prints Service

- Manuscript Podcast for convenient understanding

- Global attainment for your research

- Manuscript accessibility in different formats

(Pdf, E-pub, Full Text, Audio)

- Unceasing customer service

Track the below URL for one-step submission https://juniperpublishers.com/online-submission.php 